\title{
Formative assessment as practice: the role of students' motivation
}

\section{Martijn Leenknecht, Lisette Wijnia, Martine Köhlen, Luke Fryer, Remy Rikers} \& Sofie Loyens

To cite this article: Martijn Leenknecht, Lisette Wijnia, Martine Köhlen, Luke Fryer, Remy Rikers \& Sofie Loyens (2020): Formative assessment as practice: the role of students' motivation, Assessment \& Evaluation in Higher Education, DOI: 10.1080/02602938.2020.1765228

To link to this article: https://doi.org/10.1080/02602938.2020.1765228

\section{Published online: 18 May 2020.}

\section{Submit your article to this journal $\sqsubset$}

山ll Article views: 148

Q View related articles $\sqsubset$

View Crossmark data 


\title{
Formative assessment as practice: the role of students' motivation
}

\author{
Martijn Leenknecht ${ }^{a, b}$ (D) Lisette Wijnia ${ }^{a, b, c}$ (D), Martine Köhlen ${ }^{d}$, Luke Fryer ${ }^{\mathrm{e}}$ (D), \\ Remy Rikers ${ }^{a, f}$ (D) and Sofie Loyens ${ }^{a, f}$ (ID \\ ${ }^{a}$ Roosevelt Center for Excellence in Education, University College Roosevelt, Utrecht University, Middelburg, \\ The Netherlands; ${ }^{b} \mathrm{HZ}$ University of Applied Sciences, Vlissingen, The Netherlands; ${ }^{\mathrm{C}}$ Erasmus University \\ College, Erasmus University Rotterdam, Rotterdam, The Netherlands; ${ }^{d}$ Hogeschool Rotterdam, Rotterdam, \\ The Netherlands; ${ }^{\mathrm{e}}$ Faculty of Education, Centre for the Enhancement of Teaching and Learning, University \\ of Hong Kong, Hong Kong, SAR; ' Department of Psychology, Education, and Child Studies, Erasmus \\ University Rotterdam, Rotterdam, The Netherlands
}

\begin{abstract}
Formative assessment can be seen as an integral part of teaching and learning, as formative assessment affects students' learning and vice versa. Students' motivation can theoretically be placed at the centre of this reciprocal relationship, as formative assessment is assumed to affect students' need satisfaction of autonomy, competence and relatedness, and consequently their autonomous motivation. In the current study, two assumptions were tested empirically: formative assessment contributes to students' autonomous motivation and students' need satisfaction functions as a mediator in this relationship. The results provided support for those assumptions and indicated that more perceived use of formative assessment is associated with more feelings of autonomy and competence, and more autonomous motivation. The current study demonstrated the benefits of studying formative assessment as practice and provides encouragement for teachers to start applying formative assessment in their classroom. The theoretical model provides teachers with guidelines for an optimal implementation of formative assessment and provides researchers with a framework to study the phenomenon of 'formative assessment as practice' in more depth.
\end{abstract}

\section{KEYWORDS}

formative assessment; motivation; need

satisfaction; need frustration

Formative assessment approaches have expanded over the last decade in response to a traditional view of assessment (i.e. measurement tradition), in which assessment is solely about producing accurate estimations of students' learning to monitor and report on progress (Wiliam 2011). However, despite increased interest, these approaches to assessment have only been minimally adopted by teachers (Boud et al. 2018). Boud and colleagues (2018) reflected on this and made a case for an alternative view on assessment, contrasting with the measurement tradition: assessment as a cultural practice. In their 'assessment as practice' view, assessment is seen as a 'socially situated interpretive act' (Boud et al. 2018, p. 1109), rather than as an entity on its own: not the product of assessment, i.e. accurate estimations of students' learning, but the process of assessment is of interest when studying assessment as practice. Assessment is seen as a social activity in which a teacher, a student and peers interact and discuss the standards, criteria and 
the assessment practices. The current study presents and tests a model of formative assessment as practice with a central role for students' motivation.

\section{Formative assessment}

In the measurement tradition, formative assessment is often contrasted to summative assessment. In this view, formative assessment is about low-stakes testing, whereas summative assessment concerns high-stakes testing (Wiliam 2011). However, assessments with a summative or a formative purpose are both used to produce inferences about students' learning (Black and Wiliam 2018). Therefore, the practice view of assessment (Boud et al. 2018) adopted the understanding of 'formative' as expressed by Black and Wiliam in 2009. Assessments become formative when the inference about a student's learning is 'elicited, interpreted, and used by teachers, learners, or their peers, to make decisions about the next steps in instruction that are likely to be better, or better founded, than the decisions they would have taken in the absence of the evidence that was elicited' (Black and Wiliam 2009, p. 9). In other words, when looking at assessments as a formative practice, the roles of the teachers, the students themselves and their peers are recognised, and the developmental role of the assessment is highlighted. In this practice view, formative assessment is seen as a cyclical programme of high and low-stake tasks in which students are actively involved (as assessee and/or assessor).

The cyclical nature of formative assessment is underlined by the growing number of process models of formative assessment (e.g. Ruiz-Primo and Furtak 2007; Antoniou and James 2014), which distinguish subsequent steps in formative assessment. Ruiz-Primo and Furtak (2007) view the interplay between a teacher and a student in formative assessment as a chain of actions in their ESRU-model: the teacher elicits a response (for instance with a specific inquiry or task), the student responds, and the teacher recognises and uses the student's response in further instructions. For example, a teacher uses a quiz at the béginning of a lesson to determine the focus of his/her instruction. Antoniou and James (2014) elaborated on this model and added 'communication of expectancies and success criteria' as a first step. Additionally, they distinguish two ways in which teachers can make use of students' responses: provision of feedback and regulation of learning (e.g. incorporating repetition or modifying the task).

Although the cyclical models of formative assessment mention the students' role in formative assessment, students' active involvement is not fully elaborated upon in those models. Black and Wiliam $(2009,2018)$ do elaborate on students' active involvement in their model, as they describe three main actors in formative assessment: teachers, students and peers. They describe five key teaching strategies of formative assessment related to the questions 'Where am $1 /$ is the student going?', 'How am I/is the student doing?', and 'Where to next?'.

\section{Five key strategies of formative assessment}

The first strategy of formative assessment identified by Black and Wiliam $(2009,2018)$ is clarifying, sharing and understanding learning intentions and criteria for success. This is the first step from the model of Antoniou and James (2014). This strategy can be employed to answer the question Where is the student going?, and involves teachers, students and peers. Examples of this strategy are a teacher discussing a rubric with students, the use of exemplars to co-construct assessment criteria, and letting students formulate personal learning goals.

To find an answer to the question How is the student doing?, a teacher can make use of the second key strategy: arranging effective classroom discussions, activities and learning tasks that elicit insight into students' learning processes (Black and Wiliam 2018). The teacher initiates activities and discussions to elicit students' responses. This strategy is similar to the $E$ and $S$ part of the ESRU-model (Ruiz-Primo and Furtak 2007). These classroom practices can be done 


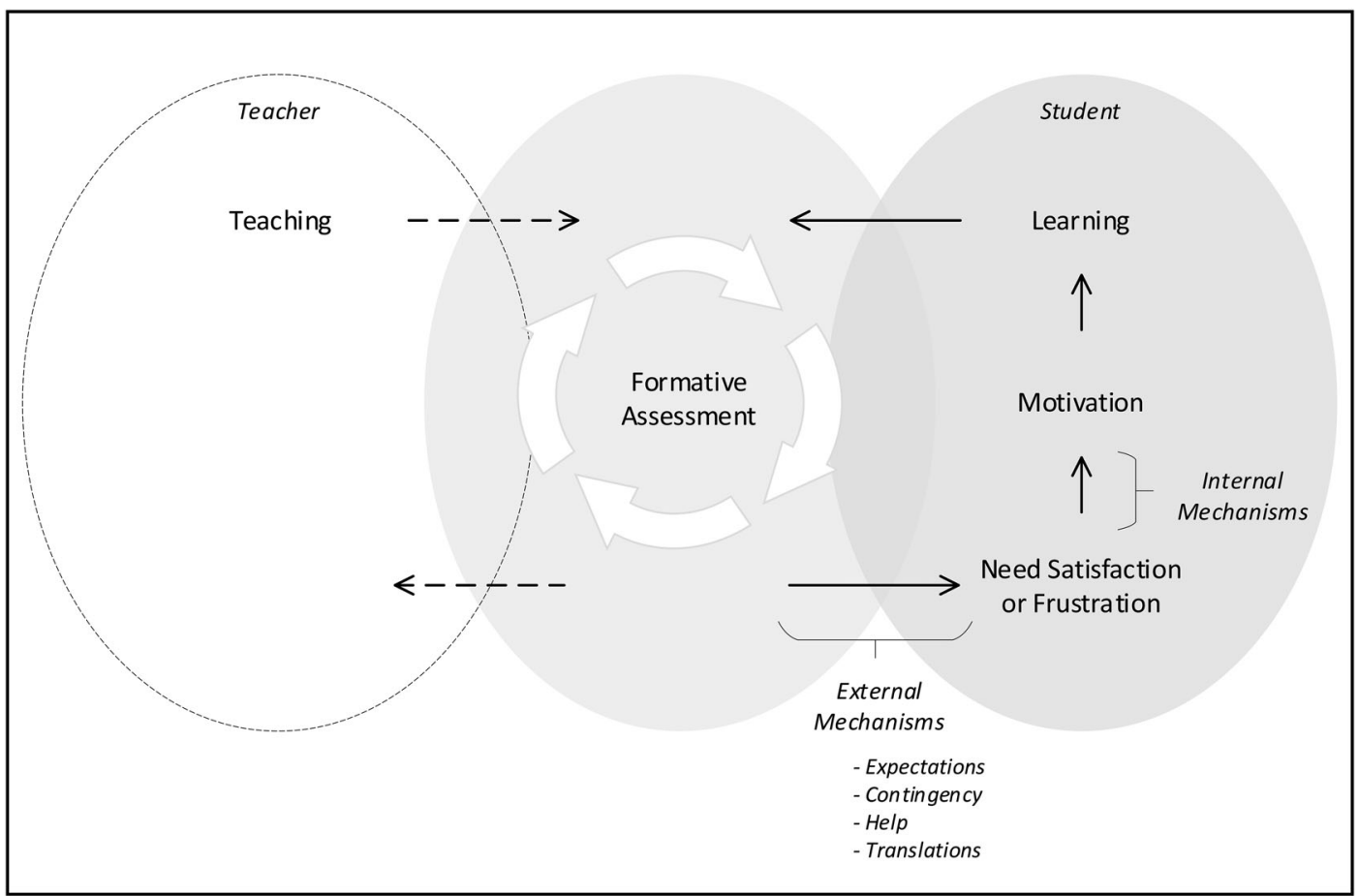

Figure 1. Formative assessment as an integral part of learning through students' need satisfaction and frustration and students' motivation.

Note. The figure shows the theoretical model. Tested models are depicted in Figures 2-5.

collaboratively, for example, when the teacher starts a class discussion to activate prior knowledge, or individually, for example when the teacher uses a quiz to test students' knowledge.

The third strategy, teacher feedback, is the teachers' response to the (elicited) insight they have gained into students' learning process, to help students determine Where to go next? (Black and Wiliam 2018). This strategy can be found in the $U$ phase of the ESRU-model (Ruiz-Primo and Furtak 2007) and the last step of the model by Antoniou and James (2014). In the teacher feedback, teachers inform students how they are doing and what they have to accomplish next. Teacher feedback can vary in nature and form, such as collectively or individually-given, written or oral, and corrective or constructive feedback (e.g. Hattie and Timperley 2007).

Not only teachers have a role in determining how students are doing and where they are going next. The fourth and fifth teaching strategies activate students as instructional resources for one another and as owners of their learning process (Black and Wiliam 2018). The most common way to adopt those strategies is by implementing peer and self-assessment, respectively. A recent meta-analysis by $\mathrm{Li}$ and colleagues (2020) showed that students benefit from peer assessment, especially when this is accompanied by peer assessment training. Panadero, Jonsson, and Botella (2017) concluded after their meta-analyses on the effect of self-assessment on self-regulated learning and students' self-efficacy that 'self-assessment is a necessity for productive learning' (p. 95). Activating students as an instructional resource is not represented in the ESRUmodel by Ruiz-Primo and Furtak (2007) or the model by Antoniou and James (2014).

\section{Formative assessment as part of students' learning}

In the practice view on formative assessment, formative assessment is not an act on its own, but rather a part of a broader context of curriculum practices (Boud et al. 2018). Formative 
assessment is seen as an integral part of education, which includes both teaching practice and students' learning. The actions, what is said and done, by both students and teachers, form the formative assessment practice. Moreover, those actions ignite future actions in formative assessment practices through students' motivation (see Figure 1). It is students' motivation that nourishes their actions (Ryan and Deci 2017), and students' motivation is affected by the formative assessment practice through the satisfaction (or frustration) of students' basic psychological needs (Skinner and Belmont 1993; Ryan and Deci 2017). As depicted in Figure 1, there is a feedback loop of formative assessment through students' motivation, which can explain why some practices are effective and others are not.

Consider the following two examples in this respect: Dave and Mike, both statistics teachers at a university. Dave makes use of weekly formative tests. Students are obliged to take the test at home after class. They are reprimanded the next lesson when they did not take the test. After taking the test, they instantly receive feedback and Dave uses the results of the tests to determine the learning objectives for the next lesson. Mike also makes use of weekly formative tests. At the start of each lesson, the students answer a short quiz about last week's learning objectives. Each question and the answers are discussed in a plenary discussion before the new lesson starts. Dave observes a decrease in students' engagement over the weeks, and the results on the weekly formative test decline, while students in Mike's class are highly motivated and engage positively in the class discussion. To explain the differences, we present a theoretical model, based on the work by Skinner (Skinner and Belmont 1993; Skinner 1995) and self-determination theory (Ryan and Deci 2017), containing two sets of mechanisms: internal and external (see Figure 1 for a schematic overview).

\section{Internal mechanisms: Students' basic psychological needs}

Students' motivation is well-described in self-determination theory (Ryan and Deci 2017). From the perspective of self-determination theory, motivation is determined by the level of selfendorsement for an activity (i.e. the level of perceived control; Reeve et al. 2008). When students experience pressure in their behaviour and feelings due to various forces (e.g. rewards or feelings of shame; Deci and Ryan 2000; Ryan and Deci 2000a, 2000b; Vansteenkiste, Lens, and Deci 2006), students experience high levels of controlled motivation. Students who are studying because they like the task or process they are engaged in or because they find it personally meaningful to engage in it, experience volition, are self-endorsed in their actions, and are autonomously motivated (Ryan and Deci 2017). Autonomous motivation is associated with higher achievement, higher persistence, and wellbeing (e.g. Taylor et al. 2014; Ryan and Deci 2017), while controlled motivation is associated with maladaptive outcomes, like procrastination, burnout and ill-being (Bartholomew et al. 2011; Ryan and Deci 2017).

According to self-determination theory, the level of motivation is determined by the satisfaction of a person's basic psychological needs for autonomy, competence and relatedness (Ryan and Deci 2017). We describe this effect of the basic needs on students' motivation as the internal mechanisms in our model (see Figure 1), as it is a process of internalisation that we can describe but not observe directly. Both the effect of need satisfaction as well as need frustration is taken into account in the current study.

In general, students experience more autonomous motivation when their basic psychological needs are satisfied (i.e. need for autonomy, competence and relatedness; Ryan and Deci 2000b; Aelterman et al. 2014). The frustration of these needs is associated with higher levels of controlled motivation (Bartholomew et al. 2011; Chen et al. 2015). Students' need for autonomy is satisfied when they experience volition and self-determination in their actions (Ryan and Deci 2000b). Competence is about experiencing effectiveness and having trust in your ability to succeed in the learning task (Skinner et al. 2008). Students' feelings of relatedness represent their 
experience of close emotional bonds and a sense of belonging to social groups (Furrer and Skinner 2003). The formative assessment in itself does promote students' feelings of competence as it provides the students with insights into their progress. However, the obligatory nature of the formative test in Dave's class from our examples harms students' feelings of autonomy.

It is assumed that all three basic psychological needs are equally important for students' autonomous motivation and that a lack of satisfaction of one of those needs will indisputably result in a lack of autonomous motivation (Ryan and Deci 2017). For example, a student who experiences a choice, recognises the relevance of what (s)he is doing and feels efficacious or competent to engage in an activity (i.e. feels autonomous and competent), but who does not feel connected to peers and his/her teacher (i.e. lacks the feeling of relatedness), is probably not enjoying school and is not autonomously motivated to study.

It is important to notice that the lack of satisfaction of a need is not the same as the frustration of the need. Need satisfaction and need frustration are not ends of the same continuum (Vansteenkiste and Ryan 2013). For example, when a student does not perceive choice, his or her need for autonomy is probably not satisfied nor frustrated. Only when a student experiences being forced to do a certain task, his or her need for autonomy will be frustrated and (s)he will be more likely to experience controlled motivation for engaging in the task.

\section{External mechanisms: Contingency, help, expectations and translations}

Students' feelings of autonomy, competence and relatedness are based on a series of experiences over time, which are the results of interactions with the context (Skinner et al. 2008). Contexts that are more need-supportive are expected to support students' need for autonomy, competence, and relatedness (Ryan and Deci 2017). Skinner's Self-System Model of Motivational Development (Skinner and Belmont 1993) provides insights into how students' need satisfaction and frustration can be affected through the context (e.g. formative assessment). Skinner (1995) distinguished four mechanisms that follow three pathways. The first pathway is setting the right conditions. This can be done by supporting contingency (mechanism 1) and providing help (mechanism 2). Second, teachers can provide clear expectations (mechanism 3) to stimulate students' actions (second pathway). Finally, the third pathway is helping students to interpret the practice, by supporting translations (mechanism 4). In our model, we describe the mechanisms as the external mechanisms (see Figure 1), as those mechanisms take place between context and student. Those external mechanisms explain why formative assessment practices result in need satisfaction or frustration.

To enable students to experience autonomy, competence and relatedness, a context should be created in which students' actions result in the desired outcomes (mechanism 1: contingency), and students get the appropriate level of help to operate those actions (mechanism 2: help). When students' means and ends are congruent with each other, we say that there is contingency. In the context of formative assessment, this means that students are provided with tasks (means) that help them to reach the learning objectives (ends). By doing so, students get the opportunity to determine their actions (autonomy) and be effective (experience competence). Wylie and Lyon (2015) conclude that contingency is essential for teacher feedback to be effective. They conclude that students should be provided with time and structures for action and revision (means). Time and opportunity to process the given constructive teacher feedback is essential to facilitate feedback uptake (Carless and Boud 2018). In our examples of Dave and Mike, the formative test and feedback are the means to obtain the learning objectives (ends). Students receive time and opportunity to process the feedback during the plenary discussion in Mike's class. However, Dave does not provide structures to process the feedback from the formative tests, making it more complicated for students to reach contingency between their actions and results. 
In addition to contingency, a teacher can create the right conditions by providing appropriate help to students (Skinner 1995). Help contains the provision of resources to obtain the learning objectives, and information on how to apply those resources, like strategy explanations and meta-cognitive or self-regulatory suggestions. Providing help to students will empower them to act autonomously and effectively (experiencing competence). Moreover, as they experience that the teacher cares about them, it contributes to students' feelings of relatedness (Furrer and Skinner 2003). Feedback that provides information on how to proceed (feed-forward) has proven to be effective (Hattie and Timperley 2007). It provides help such as information about how to apply resources (e.g. applying the feedback). Wollenschläger and colleagues (2016) found in an experimental study that feed-forward feedback contributed to students' feelings of competence. Teacher classroom practice in which constructive feedback was provided was associated with higher student perceptions of autonomy and competence in a study by Kiemer et al. (2015). Relating this to our examples of Dave and Mike, Mike provides a lot of how-to information in the plenary discussion about the quizzes, which could be considered as help. Dave is not explicitly providing help related to the formative tests.

The third external mechanism is expectations. Students will be stimulated to take action when expectations are communicated. Those expectations tell the students what action they can take (i.e. the basis for autonomy) and give them the self-efficacy beliefs (competence) to take action. A lot of research has been conducted in the context of formative assessment on the involvement of students in defining assessment criteria (e.g. Bloxham and West 2007). Defining assessment criteria make these criteria more transparent for students and helps students to understand them better (Tillema, Leenknecht, and Segers 2011). Examples of means to clarify and engage students in defining criteria for success are student training (Falchikov and Goldfinch 2000), the use of exemplars (Vu and Dall'Alba 2007) and co-construction of rubrics (Fraile, Panadero, and Pardo 2017). These means lead to a better understanding of the assessment criteria and a sense of ownership. Feedback can be used to communicate clear expectations as well. Feedback containing information about the learning goals, actual task performance, as well as information on how to proceed, contributes to students' feelings of competence (Wollenschläger et al. 2016). In contrast, evaluative or negative feedback can lead to negative outcomes such as negative affect and poor performance (Deci, Ryan, and Williams 1996; Hattie and Timperley 2007; Fong et al. 2019), as it communicates negative expectations about students' efficacy to obtain the learning objectives. In their feedback, both Dave and Mike have the opportunity to support students' self-efficacy beliefs and communicate their expectations explicitly. However, both teachers only implicitly communicate expectations with the use of formative tests or quizzes.

The fourth mechanism concerns supporting students to make appropriate translations through formative assessment. Those translations are about attribution: why did you fail or succeed, and which role did you play in this? The formative assessment provides students with clues for those translations, for example, by a teacher's remark, 'you're really good at statistics'. The translations contribute to students' feelings of competence, but also provide information about relations between teacher and students (relatedness) and who is in control (autonomy). Feedback is an evident source of information for attribution as it helps to identify and solve students' misconceptions during classroom discussions (Ruiz-Primo and Furtak 2006; Black and Wiliam 2009; Wylie and Lyon 2015). In our examples, Mike is providing more translations than Dave in response to the outcomes of the quizzes, in the plenary discussion as well as in the learning objectives for the lesson. The adjustments that Dave makes in the lesson remain invisible to students. Moreover, the instant feedback on the digital formative language test does not provide students with information about the cause of their failure, so students are not supported in their attribution of the success or failure in Dave's class. 


\section{Current study}

While both Dave and Mike incorporate a weekly formative test in their lessons, the application of formative assessment by Dave is deemed less effective. In the current study, we present a theoretical model (see Figure 1) to explain formative assessment practices, based on the work by Skinner (Skinner and Belmont 1993; Skinner 1995) and self-determination theory (Ryan and Deci 2017). Students' motivation is located in the centre of our theoretical model. The relationship between formative assessment practices and students' motivation is explained by internal and external mechanisms derived from previous research (Skinner 1995; Ryan and Deci 2017). Two basic assumptions of our theoretical model are that formative assessment and students' motivation are associated and that students' basic psychological needs satisfaction mediates this relationship. In the current study, we test those assumptions empirically. Our research questions are:

Research Question 1: Are students' perceptions of the application of formative assessment by their teacher associated with their motivation to learn?

Research Question 2: Does satisfaction of the basic psychological needs for autonomy, competence and relatedness mediate the association between students' perceptions of the application of formative assessment by their teacher and their motivation to learn?

Our theoretical model is applicable to higher education in general. Students' perceptions of the application of formative assessment in class by their teacher were used as indicators of the formative assessment practice. In class is not restricted to the physical location, but is determined by time and didactics. We have used students' perceptions as the measurement of formative assessment as students' motivation is about personal internalisation, which cannot easily be observed from outside the person (Ryan and Deci 2017). Moreover, we know from previous research a discrepancy exists between teachers' intended teaching techniques or practice and students' perceptions of it (e.g. Skinner et al. 2008; Mulliner and Tucker 2017). First, we tested the assumption that the use of formative assessment is associated with students' autonomous motivation. Baas et al. (in press) found that students' who experienced more formative assessment were more autonomously motivated. Others found support for the association between autonomous motivation and specific strategies of formative assessment, such as clarifying criteria (Haerens et al. 2019) and positive teacher feedback (Fong et al. 2019). Based on these studies, we expected that when students experience the use of formative strategies by their teacher, this contributes to their autonomous motivation. No association was expected between students' perceptions of the use of formative assessment and controlled motivation. Our hypotheses were

Hypothesis 1: Students' perceptions of the use of formative strategies by their teacher are positively associated with their autonomous motivation.

Hypothesis 2: Students' perceptions of the use of formative strategies by their teacher are not associated with their controlled motivation.

The second assumption of our theoretical model is that students' satisfaction of their need for autonomy, competence and relatedness account for the association between students' perceptions of the use of formative assessment and their autonomous motivation. Both students' need satisfaction and need frustration were taken into account. As need frustration is assumed to be associated with controlled motivation and not with autonomous motivation (Ryan and Deci 2017), we expected that need frustration does not function as a mediator in the association between students' perceptions of the use of formative assessment and their autonomous motivation. Haerens and colleagues (2019) found support for this assumption concerning the teaching strategy of clarifying criteria. Our hypotheses were: 
Table 1. Reliability of the scales and example items.

\begin{tabular}{|c|c|c|c|c|}
\hline & Number of items & Scale & $\omega$ & Example items \\
\hline \multicolumn{5}{|l|}{ AfL-DBDM } \\
\hline Clarifying criteria & 4 & $1-5$ & .861 & $\begin{array}{l}\text { During class, my teacher explains } \\
\text { what I'm learning }\end{array}$ \\
\hline Classroom discussions & 6 & $1-5$ & .721 & $\begin{array}{l}\text { The teacher makes use of } \\
\text { questions to get information } \\
\text { about my prior knowledge of } \\
\text { the topic }\end{array}$ \\
\hline Teacher feedback & 5 & $1-5$ & .779 & $\begin{array}{l}\text { The teacher makes use of } \\
\text { information about my progress } \\
\text { to give me feedback }\end{array}$ \\
\hline Self- \& peer assessment & 6 & $1-5$ & .722 & $\begin{array}{l}\text { I assess and give feedback } \\
\text { to peers }\end{array}$ \\
\hline \multicolumn{5}{|l|}{ BPNSFS } \\
\hline Autonomy satisfaction & 4 & $1-5$ & .866 & $\begin{array}{l}\text { During this course, I felt a sense of } \\
\text { choice and freedom in the } \\
\text { things I did }\end{array}$ \\
\hline Competence satisfaction & 4 & $1-5$ & .941 & $\begin{array}{l}\text { During this course, I felt confident } \\
\text { I could apply the } \\
\text { suggested strategies }\end{array}$ \\
\hline Relatedness satisfaction & 4 & $1-5$ & .935 & $\begin{array}{l}\text { During this course, I felt } \\
\text { connected to peers }\end{array}$ \\
\hline Autonomy frustration & 4 & $1-5$ & .768 & $\begin{array}{l}\text { During this course, I felt obliged } \\
\text { to think and act in a } \\
\text { certain way }\end{array}$ \\
\hline Competence frustration & 4 & $1-5$ & .750 & $\begin{array}{l}\text { During this course, I felt } \\
\text { disappointed about the } \\
\text { approach I choose to complete } \\
\text { the assignment }\end{array}$ \\
\hline Relatedness frustration & 4 & $1-5$ & .884 & $\begin{array}{l}\text { During this course, I had the } \\
\text { feeling that other students } \\
\text { didn't respect my opinion }\end{array}$ \\
\hline \multicolumn{5}{|l|}{ SRQ-a } \\
\hline Autonomous motivation & 8 & $1-4$ & .961 & $\begin{array}{c}\text { I'm motivated for this course } \\
\text { because I enjoy doing it }\end{array}$ \\
\hline Controlled motivation & 8 & $1-4$ & .886 & $\begin{array}{l}\text { I'm motivated for this course } \\
\text { because I would feel guilty if I } \\
\text { didn't do it }\end{array}$ \\
\hline
\end{tabular}

Note: Afl-DBDM = Assessment for Learning - Data-Based Decision Making; BPNSFS = Basic Psychological Need Satisfaction and Frustration Scale; SRQ-a = Academic Self-Regulation Questionnaire.

Hypothesis 3: Need satisfaction functions as a mediator in the association between students' perceptions of the use of formative strategies and their autonomous motivation.

Hypothesis 4: Need frustration does not function as a mediator in the association between students' perceptions of the use of formative strategies and their autonomous motivation.

\section{Method}

\section{Participants}

Students from 14 classes were asked to participate in this study. In total, 194 first and secondyear students $\left(M_{\text {age }}=21.10, S D_{\text {age }}=5.12 ; 57.7 \%\right.$ female) from a Dutch University of Applied Sciences participated. All classes were characterised by activating didactics in small groups (14 24 students). The students participated voluntarily, and they provided informed consent.

\section{Procedure}

We conducted a cross-sectional survey study on students' perceptions of classroom practices without intervening in class. All participants filled out a questionnaire about their perceptions of 
the use of formative strategies during the course they were enrolled in at the time of the study. Additionally, students were asked to rate their basic need satisfaction and frustration and their levels of autonomous and controlled motivation during the course. Students filled out the questionnaire during class in a lesson at the end of the semester. The researcher briefly introduced the context of the study and gave the students the choice to participate. All students present in class during the data collection decided to participate. The questionnaire was filled out with paper and pencil, and finishing the questionnaire took students 10 to $15 \mathrm{~min}$. The classroom practices on which students reflected varied among groups, as each group had a different teacher.

\section{Materials}

\section{Formative assessment scale for students}

Students' perceptions about the frequency of the application of formative strategies by their teacher were measured with the formative assessment scales from the Assessment for Learning - Data-Based Decision Making (AfL-DBDM) questionnaire developed by Kippers and colleagues (2018). In this study, the Dutch student version of the AfL-DBDM questionnaire by Wolterinck, Schildkamp, and Visscher (2020) was used. This questionnaire consists of 21 statements about the five formative strategies by Black and Wiliam $(2009,2018)$ and a subscale on data use for instruction (which was not included in this study). Self and peer assessment were combined into one subscale in this questionnaire, after confirmatory factor analysis (Kippers et al. 2018). Students indicated to what extent they agreed with the statements on a 5-point Likert scale ranging from 1 (completely disagree) to 5 (completely agree). See Table 1 for example items and reliability coefficients. McDonald's (1970) omega was used for calculating reliability coefficients, as a correlated factor structure was expected (Sijtsma 2009; Cho and Kim 2015). Abbreviated names for the constructs were used in the tables and the results section for clarity reasons. For example, the strategy 'Engineering effective classroom discussions, activities, and learning tasks that elicit insight into students' learning processes' was abbreviated to 'classroom discussions'. However, the scope of the constructs remained unchanged.

\section{The basic psychological need satisfaction and frustration scale}

The Dutch version of the Basic Psychological Need Satisfaction and Frustration Scale (BPNSFS; Chen et al. 2015) was used to measure the satisfaction and frustration of students' basic psychological needs. In total, this scale consists of three subscales (one per psychological need) for satisfaction and three for frustration. The questionnaire consists of 24 items (see Table 1 for example items per subscale), and students were asked to indicate to what extent they agreed with the statements on a 5-point Likert scale ranging from 1 (completely disagree) to 5 (completely agree). Reliability coefficients are displayed in Table 1.

\section{Academic self-regulation questionnaire}

The Dutch translation of the task-specific Academic Self-Regulation Questionnaire (SRQ-a) was used to measure students' autonomous and controlled motivation. The scale was developed by Ryan and Connell (1989; Vansteenkiste et al. 2009). The questionnaire consists of 16 items. A 4point Likert scale ranging from 1 (completely disagree) to 4 (completely agree) was used to measure students' motivation (see Table 1 for example items and reliability coefficients). 


\section{Analyses}

Data were inspected before analyses. Firstly, five participants who did not fill out the questionnaire completely (i.e. missing value for more than one item per construct) or accurately (i.e. all the same scores across constructs) were removed from the dataset. When only one item-value was missing per scale, the average score was calculated, excluding the missing value (i.e. person mean substitution; McDonald, Thurston, and Nelson 2000). Secondly, eight univariate or multivariate outliers on the construct level were excluded from the analyses. Scores were considered outliers when they were three or more standard deviations above or below the mean score (Osborne and Overbay 2004). Excluding the outliers did not have an impact on the results, as similar patterns in the results were found before exclusion. After data inspection, 181 respondents were included in the dataset. All scores were standardised before the analyses to prevent deviation of the results due to various Likert-scales.

Students' basic psychological needs were tested as mediators, using bootstrapping with PROCESS v3.4 for SPSS 25 (Hayes 2017). Multiple mediation models were used to test the basic psychological need satisfaction and frustration as a set of mediators and to be able to conclude which of them has the ability to mediate the association between formative strategies and motivation, controlling for all other mediators. A 95\% bias-corrected and accelerated confidence interval (Efron 1987) for indirect effects was estimated to establish the statistical significance of the indirect effects.

\section{Results}

\section{Descriptive statistics}

Mean scores and correlations of students' perceptions of the use of formative strategies, students' basic psychological need satisfaction and frustration, and their autonomous and controlled motivation are displayed in Table 2. Students reported slightly more clarifying criteria (Strategy 1 ) and classroom discussion practices (Strategy 2) than teacher feedback (Strategy 3) or self and peer assessment (Strategy 4). Correlations among students' perceptions of formative strategies were moderate.

Students reported on average that they experienced autonomous motivation as well as controlled motivation to study (see Table 2). Their basic psychological needs were more satisfied than frustrated. Relatedness satisfaction was reported highest (see Table 2). Students' autonomous and controlled motivation were not correlated $(r=-.007, p=.926)$. At most, moderate correlations were found between autonomy satisfaction and competence satisfaction and autonomy frustration and competence frustration. Moderately negative correlations were found between the need satisfaction and frustration equivalences (see Table 2).

\section{Hypotheses 1 and 2: Association between perceived formative strategies and students' motivation}

We hypothesised that students' perceptions of formative strategy use were statistically significantly associated with their autonomous motivation (Hypothesis 1), but not with controlled motivation (Hypothesis 2). Hypothesis one was supported: students' autonomous motivation was statistically significantly associated with their perceptions of clarifying criteria $(b=.399, p<$ $.001)$, classroom discussions $(b=.378, p<.001)$, teacher feedback $(b=.344 p<.001)$ and self and peer assessment $(b=.248, p<.001)$. Students' controlled motivation was only statistically significantly associated with perceptions of the use of classroom discussions $(b=.159 p<.05)$. Perceptions of clarifying criteria, teacher feedback and self and peer assessment were not statistically significantly associated with controlled motivation. This means that Hypothesis two was 


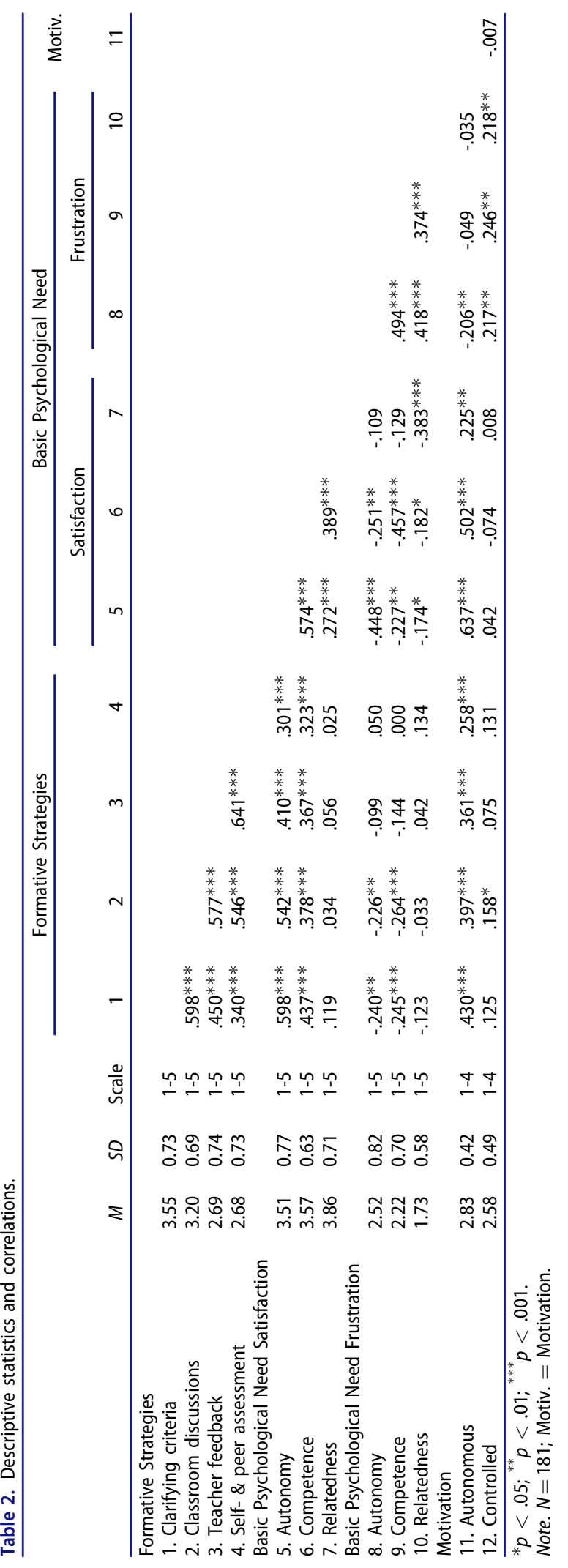


Table 3. Indirect effects (i.e. mediation) of formative strategies on autonomous motivation through need satisfaction and need frustration.

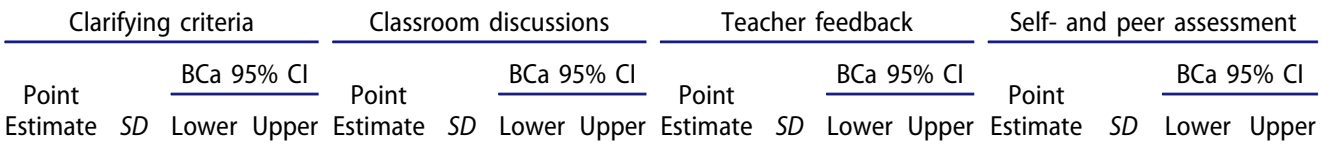

\begin{tabular}{|c|c|c|c|c|c|c|c|c|c|c|c|c|c|c|c|c|}
\hline AS & .257 & .058 & .155 & .382 & .235 & .053 & .142 & .353 & .185 & .047 & .103 & .290 & (146. & .039 & .079. & .233 \\
\hline CS & .119 & .041 & .050 & 213 & .107. & .038 & .042 & 191 & 100 & .036 & .039 & 181 & .093 & .038 & .034 & .185 \\
\hline RS & .002 & .010 & -.014 & .032 & .001 & .007 & -.008 & .021 & .001 & .007 & -.009 & .024 & .000 & .006 & -.012 & .017 \\
\hline $\mathrm{AF}$ & .006 & .017 & -.025 & .043 & .006 & .017 & -.022 & .048 & .003 & .009 & -.009 & .028 & -.001 & .006 & -.022 & .007 \\
\hline CF & -.047 & .021 & -.101 & -.015 & -.054 & .026 & -.120 & -.017 & -.028 & .017 & -.072 & -.003 & .000 & .014 & -.029 & .031 \\
\hline $\mathrm{RF}$ & -.006 & .011 & -.038 & .009 & -.001 & .006 & -.025 & .006 & .002 & .007 & -.006 & .026 & .006 & .013 & -.013 & .043 \\
\hline Total & .332 & .061 & .220 & .463 & .293 & .057 & .190 & .417 & .261 & .055 & .163 & .376 & .245 & .051 & .152 & .350 \\
\hline
\end{tabular}

Note: $\mathrm{BCa} 95 \% \mathrm{Cl}=95 \%$ bias-corrected and accelerated confidence interval (Efron 1987); AS=autonomy satisfaction; $\mathrm{CS}=$ competence satisfaction; $\mathrm{RS}=$ relatedness satisfaction; $\mathrm{AF}=$ autonomy frustration; $\mathrm{CF}=$ competence frustration; $\mathrm{RF}=$ relatedness frustration.

supported for students' perceptions of the occurrence of clarifying criteria, teacher feedback and self and peer assessment, but not for classroom discussions.

\section{Hypotheses 3 and 4: Mediation effects}

The mediating effect of need satisfaction and frustration on the association between perceptions of the use of formative assessment and motivation was tested using bootstrapping. All mediators were tested simultaneously. Significant indirect effects indicate mediation (Hayes 2017). Specific indirect effects are displayed in Table 3 for autonomous motivation and Table 4 for controlled motivation. In Figures $2-5$, the direct and total indirect effects of the perceptions of formative strategy use on autonomous motivation are displayed for each formative strategy separately. The coefficients of the associations between the perceptions of formative strategy use and the mediators (i.e. need support or frustration) and autonomous/controlled motivation, as well as the level of statistical significance, are provided in the figures.

\section{Autonomous motivation}

The total indirect effects of all perceptions of formative strategy use on autonomous motivation were statistically significant (see Figures 2-5 and Table 3), indicating that the association between formative strategy use and autonomous motivation was mediated through students' needs (as hypothesised in Hypothesis 3). Examining the specific indirect effects (see Table 3), it can be concluded that the positive effect of students' perceptions of formative strategy use on students' autonomous motivation is mediated through autonomy satisfaction and competence satisfaction for all four strategies. The 95\% bias-corrected and accelerated confidence intervals (Efron 1987) do not contain zero. As relatedness satisfaction was not a mediator, Hypothesis three was only partially supported. We hypothesised that need frustration would not function as a mediator (Hypothesis 4). According to the specific indirect effects, competence frustration was a statistically significant mediator of the positive effects of students' perceptions of clarifying criteria, classroom discussions and teacher feedback on autonomous motivation. These results indicate that Hypothesis four was supported for autonomy and relatedness frustration, but not for competence frustration.

\section{Controlled motivation}

The total indirect effects of students' perceptions of clarifying criteria, classroom discussions, teacher feedback, and self and peer assessment on controlled motivation were not statistically 
Table 4. Indirect effects (i.e. mediation) of formative strategies on controlled motivation through need satisfaction and need frustration.

\begin{tabular}{|c|c|c|c|c|c|c|c|c|c|c|}
\hline \multicolumn{2}{|c|}{ Clarifying criteria } & \multicolumn{3}{|c|}{ Classroom discussions } & \multicolumn{3}{|c|}{ Teacher feedback } & \multicolumn{3}{|c|}{ Self- and peer assessment } \\
\hline & & & & $\mathrm{Cl}$ & & & $\mathrm{BC}$ & & & $6 \mathrm{Cl}$ \\
\hline timate $S D$ & Lower Upper & Estimate & $S D$ & Lower Upper & Estimate & $S D$ & Lower Upper & Estimate & $S D$ & Lower Upp \\
\hline
\end{tabular}

\begin{tabular}{|c|c|c|c|c|c|c|c|c|c|c|c|c|c|c|c|c|}
\hline AS & .052 & .075 & -.101 & .195 & .042 & .065 & -.087 & 170 & .077 & .045 & -.002 & .179 & .057 & .034 & -.001 & .137 \\
\hline CS & -.055 & .047 & -.155 & .034 & -.044 & .042 & -.136 & .032 & -.043 & .041 & -.135 & .029 & -.043 & .037 & -.129 & .020 \\
\hline RS & .012 & .015 & -.005 & .062 & .004 & .012 & -.011 & .043 & .005 & .011 & -.007 & .044 & .002 & .011 & -.011 & .039 \\
\hline $\mathrm{AF}$ & -.035 & .027 & -.099 & .010 & -.034 & .028 & -.110 & .008 & -.017 & .018 & -.071 & .003 & .008 & .015 & -.009 & .058 \\
\hline$C F$ & -.033 & .025 & -.095 & .005 & -.043 & .030 & -.118 & .002 & -.017 & .018 & -.071 & .005 & .000 & .011 & -.022 & .023 \\
\hline RF & -.020 & .018 & -.077 & .001 & -.005 & .012 & -.041 & .013 & .006 & .014 & -.010 & .053 & .020 & .018 & -.002 & .076 \\
\hline Total & -.078 & .070 & -.232 & .050 & -.080 & .060 & -.211 & .030 & .012 & .046 & -.078 & .103 & .045 & .043 & -.037 & .132 \\
\hline
\end{tabular}

Note: $\mathrm{BCa} 95 \% \mathrm{Cl}=95 \%$ bias-corrected and accelerated confidence interval (Efron 1987); AS=autonomy satisfaction; $\mathrm{CS}=$ competence satisfaction; $\mathrm{RS}=$ relatedness satisfaction; $\mathrm{AF}=$ autonomy frustration; $\mathrm{CF}=$ competence frustration; $\mathrm{RF}=$ relatedness frustration.

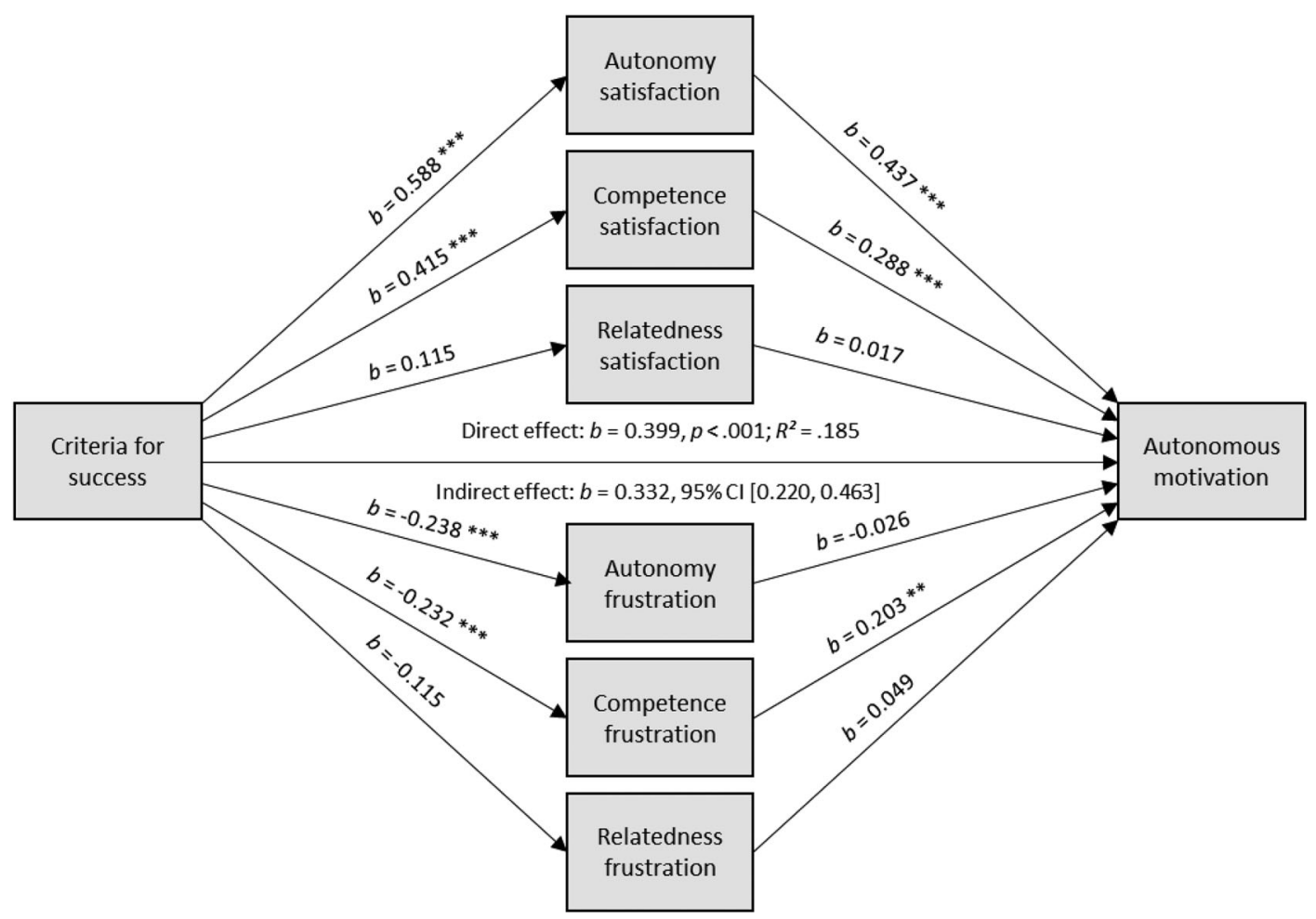

${ }^{*} p<.05, * * p<.01, * * * p<.001$

Figure 2. Mediation model of criteria for success and autonomous motivation.

significant (see Table 4). Moreover, no statistically significant specific indirect effects were found, meaning that no mediation effects were found. For that reason, we did not depict mediation models for controlled motivation.

\section{Discussion}

In the current study, we investigated formative assessment as practice (Boud et al. 2018). We located formative assessment as an integral part of students' learning and tested a theoretical 


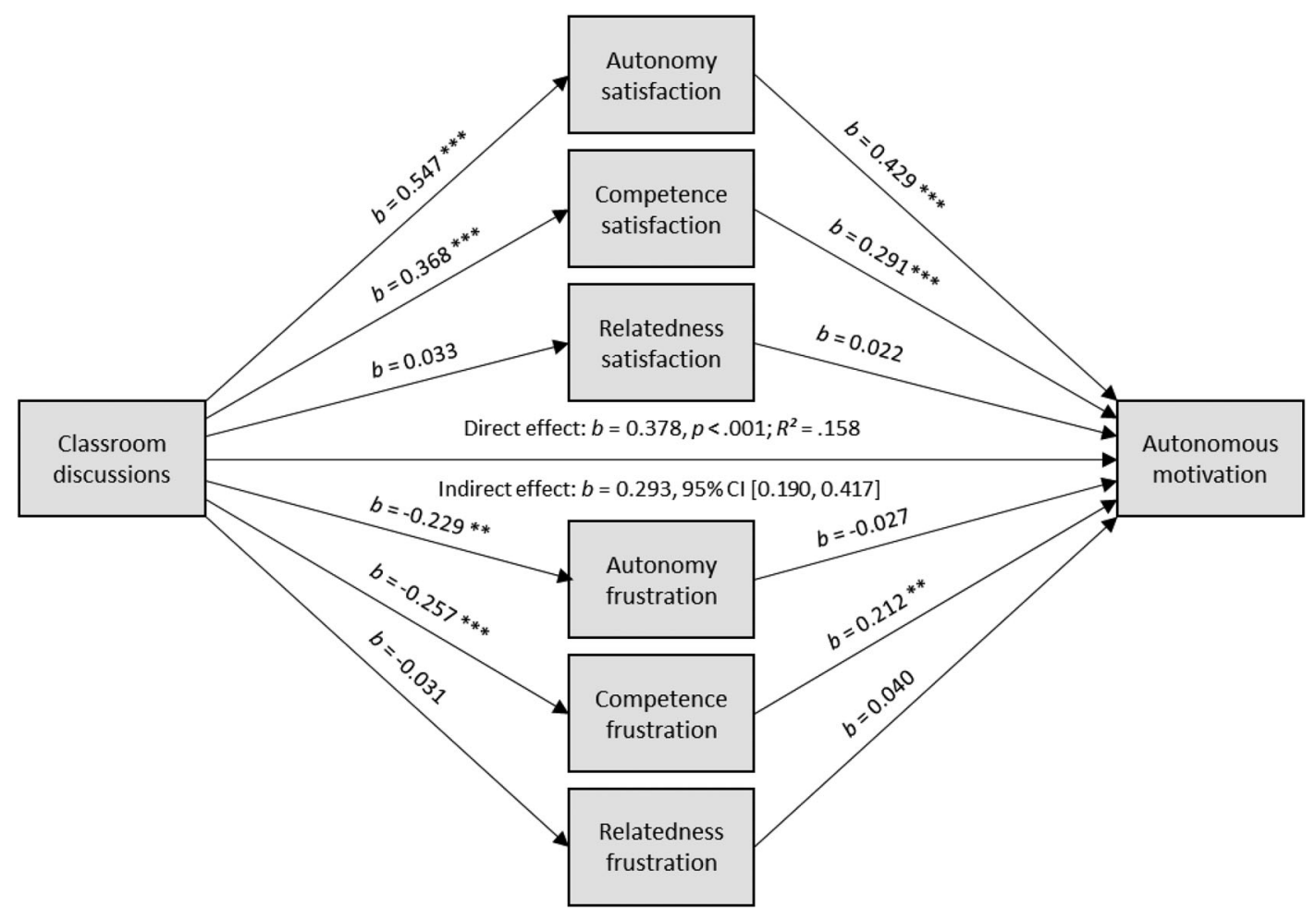

$* p<.05, * * p<.01, * * * p<.001$

Figure 3. Mediation model of classroom discussions and autonomous motivation.

model that described a feedback loop between formative assessment practice and students' learning through students' motivation (see Figure 1). In our empirical cross-sectional study, we examined two assumptions of our theoretical model: 1) the assumption that the perceived application of formative assessment is associated with students' motivation to learn (Hypotheses 1 \& 2); and 2) the assumption that students' satisfaction of their basic psychological needs for autonomy, competence and relatedness mediate the association between students' perceptions of formative assessment use and their autonomous motivation (Hypotheses $3 \& 4$ ).

\section{Hypotheses 1 and 2: the association between students' perceptions of formative assessment and their motivation}

The results of the current study are in line with previous research (e.g. Haerens et al. 2019; Baas et al. in press), and indicated that students' perceptions of the application of formative strategies by their teacher were associated with their autonomous motivation. However, the results also indicated that students' perceptions of one of the formative strategies, 'arranging effective classroom discussions, activities and learning tasks that elicit insight into students' learning processes' (classroom discussions), was positively associated with students' controlled motivation. Thus, students who experienced more teacher use of classroom discussions reported higher autonomous and higher controlled motivation. This is in contrast to what we hypothesised (Hypothesis 2), meaning that classroom discussions do not solely result in more autonomous motivation of the students. The way classroom discussions are applied by the teacher matters. Ruiz-Primo and 


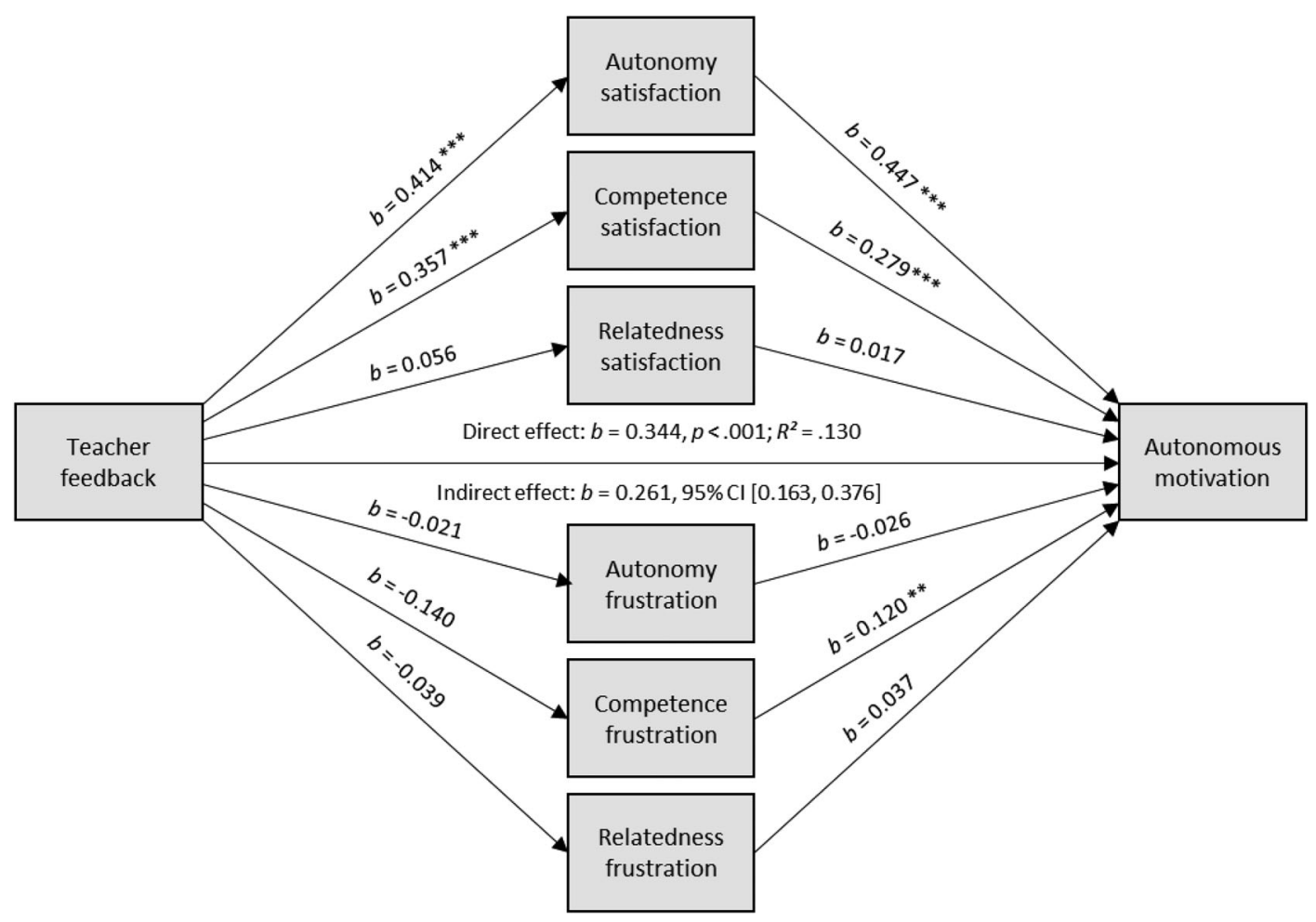

$* p<.05, * * p<.01, * * * p<.001$

Figure 4. Mediation model of teacher feedback and autonomous motivation.

Furtak (2006) pointed out that the teacher plays an important role in class discussions. The teacher can control the flow of the discussion and, in this way, possibly frustrate students' need for autonomy (Stroet, Opdenakker, and Minnaert 2013). However, how the classroom discussions were applied was not taken into account in the current study.

For the other strategies, students' perceptions of the use of those strategies were not associated with their controlled motivation. This result is in line with Hypothesis two and indicates that in general, the use of formative assessment by teachers is beneficial for students' motivation. Teachers who, as reported by students, use formative strategies, have students in their classrooms who are more autonomously motivated.

\section{Hypotheses 3 and 4: the role of basic psychological need satisfaction and frustration}

As hypothesised, the relation between the perceived use of formative strategies and autonomous motivation was found to be mediated by students' basic psychological needs. Concerning the formative strategies of clarifying and engaging students in setting criteria for success (Strategy 1), classroom discussions (Strategy 2), teacher feedback (Strategy 3) and self and peer assessment (Strategy $4 \& 5$ ), this hypothesised mediation effect was confirmed for autonomy satisfaction and competence satisfaction (Hypothesis 3). No mediation effect was found for relatedness satisfaction.

For autonomy and competence, our results are in line with the conclusions of the study by Haerens and colleagues (2019). However, they concluded that knowledge about the criteria 


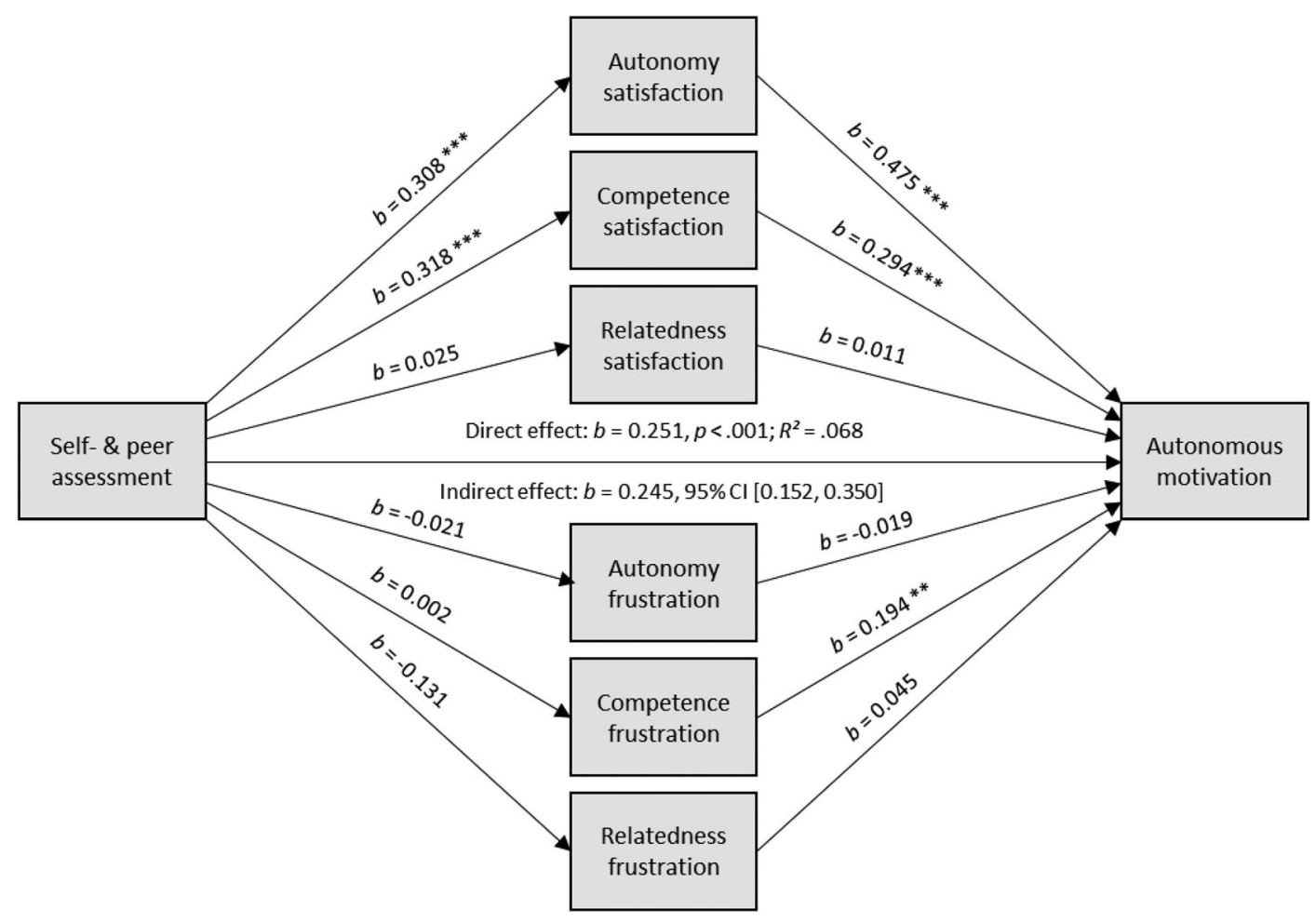

$* p<.05, * * p<.01, * * * p<.001$

Figure 5. Mediation model of self- and peer assessment and autonomous motivation.

contributed to students' perceptions of being in charge (autonomy), being effective (competence), and having strong relationships with their teacher (relatedness). That we did not find a mediation effect for relatedness satisfaction underlines the significance of studying students' need satisfaction with separate measures instead of a composite score as Haerens and colleagues (2019) did. Based on our results, we can come to a more fine-grained conclusion that relatedness satisfaction does not play a significant role in the association between the students' perceptions of the application of formative assessment and students' autonomous motivation.

A statistically significant mediation effect was found for competence frustration in the relation between perceived use of clarifying criteria (Strategy 1), classroom discussions (Strategy 2) and teacher feedback (Strategy 3) on the one hand, and autonomous motivation on the other hand. More use of clarifying and engaging in setting criteria for success, classroom discussions and teacher feedback was associated with less competence frustration, which in turn was associated with more autonomous motivation. This result is contrary to our hypothesis (Hypothesis 4). In line with self-determination theory, we expected that less competence frustration would be associated with less controlled motivation and would not be associated with autonomous motivation (Ryan and Deci 2017).

A possible explanation of those unexpected results could be transparency. As one of the objectives for the use of formative assessment is to increase transparency for students (Tillema, Leenknecht, and Segers 2011), it is not surprising that three of the five strategies contribute to both competence satisfaction and frustration. Being engaged in formative assessment leads to less confusion about the task, criteria and approach (i.e. competence frustration) as well as more confidence in one's own ability to complete the task (i.e. competence satisfaction). 
That both competence satisfaction and frustration were found to function as statistically significant mediators in the association between students' perceptions of the use of formative assessment strategies and autonomous motivation underlines that competence satisfaction and frustration are not opposite ends of the same continuum (Vansteenkiste and Ryan 2013). Both explain variance in students' motivation. Moreover, it shows that formative assessment is mainly affecting students' feelings of competence, and thus can be considered a competencesupportive practice, similar to providing structure, which provides students' perceived control and motivation (Skinner 1995). Structured contexts have shown to promote students' competence satisfaction and reduce their competence frustration (e.g. Stroet, Opdenakker, and Minnaert 2013).

\section{Limitations and directions for future research}

The current study was a first attempt to model formative assessment as practice. Two basic assumptions of our theoretical model (see Figure 1) were tested and confirmed. However, the other aspects of the model (e.g. the external mechanisms) were not tested. It seems worthwhile to study in more detail how formative assessment affects students' self-perceptions of autonomy, competence and relatedness, for example, by focussing on one of the external mechanisms (see Figure 1) or by adopting a more qualitative research approach.

We made use of students' perceptions about the use of formative assessment. These perceptions did not give us insight into how formative assessment was applied. This could explain some unexpected relationships we found, for example, the mediating effect of competence frustration. We suggest studying the application of formative assessment in more detail. Our theoretical model can be useful in analysing in depth what processes are going on in the formative assessment practice, especially when focussing on students' roles.

It seems worthwhile to include the teacher's role in further research. Not only the formative assessment in itself but also the interpersonal relationship between teachers and students has been found to be important for students' autonomous motivation (e.g. Leenknecht et al. 2017; Haerens et al. 2019). Moreover, some recent studies have found that teachers' competence to apply formative assessment successfully determines the effectiveness of formative assessment (Heitink et al. 2016). We expect this is also the case for the effect of formative assessment practice on students' autonomous motivation.

The current study is a descriptive study that confirms, to a large extent, the assumptions based on our theoretical model. However, no conclusions can be drawn about the causality of relationships. Future research in which formative assessment is manipulated and applied in different conditions is necessary to establish the causality of the proposed self-system feedback loop.

\section{Implications}

The results of the current study showed that not one strategy of formative assessment is favourable above others. Students' perceptions of the use of all strategies were associated with higher self-perceptions (i.e. need satisfaction) of autonomy and competence and, consequently, more autonomous motivation.

Our theoretical model, which is based on the Self-System Model of Motivational Development (Skinner and Belmont 1993), provides insight into how formative assessment influences students' learning. The theoretical model can be used to explain the effectiveness of formative assessment, and the external and internal mechanisms can be used to study formative assessment practice in depth. Even though the current study provided proof for two fundamental assumptions of the model, more fine-tuning of the model is recommended, for example, about the role of 
relatedness satisfaction. With the introduction of the theoretical model, we contribute to the debate and research on formative assessment as practice (Boud et al. 2018).

For teachers who are thinking about applying formative assessment in their lessons, the current study is an encouragement to start practicing. We showed the beneficial association between students' perceptions of the application of formative assessment and students' autonomous motivation. Moreover, the current study provides teachers with a framework to apply during curriculum and course development. The external mechanisms of contingency, help, expectations and translations can help teachers to evaluate their formative assessment as practice.

\section{Conclusion}

The results of the current study show that the perceived application of formative assessment strategies by teachers is associated with students' feelings of autonomy and competence. More perceived use of formative assessment is associated with more perceived autonomy and competence (both in more competence satisfaction and less frustration), and more autonomous motivation. This means that we found support for two basic assumptions of our theoretical model to explain formative assessment as practice. The application of formative assessment contributes to students' need satisfaction and, consequently, autonomous motivation. Students' motivation feeds back into the formative assessment practice, and a new feedback loop begins.

\section{Disclosure statement}

No potential conflict of interest was reported by the author(s).

\section{ORCID}

Martijn Leenknecht (iD http://orcid.org/0000-0003-3494-9057

Lisette Wijnia (D) http://orcid.org/0000-0001-7395-839X

Luke Fryer (iD http://orcid.org/0000-0001-6250-5950

Remy Rikers (iD http://orcid.org/0000-0002-4722-1455

Sofie Loyens (iD http://orcid.org/0000-0002-2419-1492

\section{References}

Aelterman, N., M. Vansteenkiste, L. Van den Berghe, J. De Meyer, and L. Haerens. 2014. "Fostering a NeedSupportive Teaching Style: Intervention Effects on Physical Education Teachers' Beliefs and Teaching Behaviors." Journal of Sport and Exercise Psychology 36 (6): 595-609. doi:10.1123/jsep.2013-0229.

Antoniou, P., and M. James. 2014. "Exploring Formative Assessment in Primary School Classrooms: Developing a Framework of Actions and Strategies." Educational Assessment, Evaluation and Accountability 26 (2): 153-176. doi: 10.1007/s11092-013-9188-4.

Baas, D., M. Vermeulen, J. Castelijns, R. Martens, and M. Segers. in press. "Portfolios as a Tool for AfL and Student Motivation: Are They Related?" Assessment in Education: Principles, Policy \& Practice: 1-19. doi:10.1080/0969594X. 2019.1653824.

Bartholomew, K. J., N. Ntoumanis, R. M. Ryan, J. A. Bosch, and C. Thøgersen-Ntoumani. 2011. "Self-Determination Theory and Diminished Functioning: The Role of Interpersonal Control and Psychological Need Thwarting." Personality and Social Psychology Bulletin 37 (11): 1459-1473. doi:10.1177/0146167211413125.

Black, P., and D. Wiliam. 2009. "Developing the Theory of Formative Assessment." Educational Assessment, Evaluation and Accountability 21 (1): 5-31. doi:10.1007/s11092-008-9068-5.

Black, P., and D. Wiliam. 2018. "Classroom Assessment and Pedagogy." Assessment in Education: Principles, Policy \& Practice 25 (6): 551. doi:10.1080/0969594X.2018.1441807.

Bloxham, S., and A. West. 2007. "Learning to Write in Higher Education: Students' Perceptions of an Intervention in Developing Understanding of Assessment Criteria." Teaching in Higher Education 12 (1): 77-89. doi:10.1080/ 13562510601102180 . 
Boud, D., P. Dawson, M. Bearman, S. Bennett, G. Joughin, and E. Molloy. 2018. "Reframing Assessment Research: Through a Practice Perspective." Studies in Higher Education 43 (7): 1107-1118. doi:10.1080/03075079.2016. 1202913.

Carless, D., and D. Boud. 2018. "The Development of Student Feedback Literacy: Enabling Uptake of Feedback." Assessment \& Evaluation in Higher Education 43 (8): 1315-1325. doi:10.1080/02602938.2018.1463354.

Chen, B., M. Vansteenkiste, W. Beyers, L. Boone, E. L. Deci, J. Van der Kaap-Deeder, B. Duriez, et al. 2015. "Basic Psychological Need Satisfaction, Need Frustration, and Need Strength across Four Cultures." Motivation and Emotion 39 (2): 216-236. doi:10.1007/s11031-014-9450-1.

Cho, E., and S. Kim. 2015. "Cronbach's Coefficient Alpha: Well Known but Poorly Understood." Organizational Research Methods 18 (2): 207-230. doi:10.1177/1094428114555994.

Deci, E. L., and R. M. Ryan. 2000. "The "What" and "Why" of Goal Pursuits: Human Needs and the SelfDetermination of Behavior." Psychological Inquiry 11 (4): 227-268. doi:10.1207/S15327965PLI1104_01.

Deci, E. L., R. M. Ryan, and G. C. Williams. 1996. "Need Satisfaction and the Self-Regulation of Learning." Learning and Individual Differences 8 (3): 165-183. doi:10.1016/S1041-6080(96)90013-8.

Efron, B. 1987. "Better Bootstrap Confidence Intervals." Journal of the American Statistical Association 82 (397): 171-185. doi:10.2307/2289144.

Falchikov, N., and J. Goldfinch. 2000. "Student Peer Assessment in Higher Education: A Meta-Analysis Comparing Peer and Teacher Marks." Review of Educational Research 70 (3): 287-322. doi:10.3102/00346543070003287.

Fong, C. J., E. A. Patall, A. C. Vasquez, and S. Stautberg. 2019. "A Meta-Analysis of Negative Feedback on Intrinsic Motivation." Educational Psychology Review 31 (1): 121-162. doi:10.1007/s10648-018-9446-6.

Fraile, J., E. Panadero, and R. Pardo. 2017. "Co-Creating Rubrics: The Effects on Self-Regulated Learning, Self-Efficacy and Performance of Establishing Assessment Criteria with Students." Studies in Educational Evaluation 53: 69-76. doi:10.1016/j.stueduc.2017.03.003.

Furrer, C., and E. Skinner. 2003. "Sense of Relatedness as a Factor in Children's Academic Engagement and Performance." Journal of Educational Psychology 95 (1): 148-162. doi:10.1037/0022-0663.95.1.148.

Haerens, L., C. Krijgsman, A. Mouratidis, L. Borghouts, G. Cardon, and N. Aelterman. 2019. "How Does Knowledge about the Criteria Fora n Upcoming Test Relate to Adolescents' Situational Motivation in Physical Education? a Self-Determination Theory Approach." European Physical Education Review 25 (4): 983-1001. doi:10.1177/ $1356336 \times 18783983$.

Hattie, J., and H. Timperley. 2007. "The Power of Feedback." Review of Educational Research 77 (1): 81-112. doi:10. 3102/003465430298487.

Hayes, A. F. 2017. "Introduction to Mediation." Moderation, and Conditional Process Analysis: A Regression-Based Approach. New York: Guilford Press.

Heitink, M. C., F. M. Van der Kleij, B. P. Veldkamp, K. Schildkamp, and W. B. Kippers. 2016. "A Systematic Review of Prerequisites for Implementing Assessment for Learning in Classroom Practice." Educational Research Review 17: 50-62. doi:10.1016/j.edurev.2015.12.002.

Kiemer, K., A. Gröschner, A.-K. Pehmer, and T. Seidel. 2015. "Effects of a Classroom Discourse Intervention on Teachers' Practice and Students' Motivation to Learn Mathematics and Science." Learning and Instruction 35: 94-103. doi:10.1016/j.learninstruc.2014.10.003.

Kippers, W. B., C. H. D. Wolterinck, K. Schildkamp, C. L. Poortman, and A. J. Visscher. 2018. "Teachers' Views on the Use of Assessment for Learning and Data-Based Decision Making in Classroom Practice." Teaching and Teacher Education 75: 199-213. doi:10.1016/j.tate.2018.06.015.

Leenknecht, M. J. M., L. Wijnia, S. M. M. Loyens, and R. M. J. P. Rikers. 2017. "Need-Supportive Teaching in Higher Education: Configurations of Autonomy Support, Structure, and Involvement." Teaching and Teacher Education 68: 134-142. doi:10.1016/j.tate.2017.08.020.

Li, H., Y. Xiong, C. V. Hunter, X. Guo, and R. Tywoniw. 2020. "Does Peer Assessment Promote Student Learning? a Meta-Analysis." Assessment \& Evaluation in Higher Education 45 (2): 193-211. doi:10.1080/02602938.2019.1620679.

McDonald, R. P. 1970. "Theoretical Foundations of Principal Factor Analysis, Canonical Factor Analysis, and Alpha Factor Analysis." British Journal of Mathematical and Statistical Psychology 23 (1): 1-21. doi:10.1111/j.2044-8317. 1970.tb00432.x.

McDonald, R. A., P. W. Thurston, and M. R. Nelson. 2000. "A Monte Carlo Study of Missing Item Methods." Organizational Research Methods 3 (1): 71-92. doi:10.1177/109442810031003.

Mulliner, E., and M. Tucker. 2017. "Feedback on Feedback Practice: Perceptions of Students and Academics." Assessment \& Evaluation in Higher Education 42 (2): 266-288. doi:10.1080/02602938.2015.1103365.

Osborne, J. W., and A. Overbay. 2004. "The Power of Outliers (and Why Researchers Should Always Check for Them)." Practical Assessment, Research, and Evaluation (6): 9. http://PAREonline.net/getvn.asp?v=9\&n=6.

Panadero, E., A. Jonsson, and J. Botella. 2017. "Effects of Self-Assessment on Self-Regulated Learning and SelfEfficacy: Four Meta-Analyses." Educational Research Review 22: 74-98. doi:10.1016/j.edurev.2017.08.004.

Reeve, J., R. M. Ryan, E. L. Deci, and H. Jang. 2008. "Understanding and Promoting Autonomous Self-Regulation: A Self-Determination Theory Perspective." In D. Schunk and B. Zimmerman (Eds.), Motivation and Self-Regulated Learning: Theory, Research, and Application, 223-244. Mahwah, NJ: Lawrence Erlbaum Associates Publishers. 
Ruiz-Primo, M. A., and E. M. Furtak. 2006. "Informal Formative Assessment and Scientific Inquiry: Exploring Teachers' Practices and Student Learning." Educational Assessment 11 (3-4): 237-263. doi:10.1080/10627197.2006.9652991.

Ruiz-Primo, M. A., and E. M. Furtak. 2007. "Exploring Teachers' Informal Formative Assessment Practices and Students' Understanding in the Context of Scientific Inquiry." Journal of Research in Science Teaching 44 (1): 57-84. doi:10.1002/tea.20163.

Ryan, R. M., and J. P. Connell. 1989. "Perceived Locus of Causality and Internalization: Examining Reasons for Acting in Two Domains." Journal of Personality and Social Psychology 57 (5): 749-761. doi:10.1037/0022-3514.57.5.749.

Ryan, R. M., and E. L. Deci. 2000a. "Intrinsic and Extrinsic Motivations: Classic Definitions and New Directions." Contemporary Educational Psychology 25 (1): 54-67. doi:10.1006/ceps.1999.1020.

Ryan, R. M., and E. L. Deci. 2000b. "Self-Determination Theory and the Facilitation of Intrinsic Motivation, Social Development, and Well-Being." American Psychologist 55 (1): 68-78. doi:10.1037/0003-066X.55.1.68.

Ryan, R. M., and E. L. Deci. 2017. "Self-Determination Theory: Basic Psychological Needs in Motivation." Development, and Wellness. New York, NY: Guilford Press.

Sijtsma, K. 2009. "On the Use, the Misuse, and the Very Limited Usefulness of Cronbach's Alpha." Psychometrika 74 (1): 107-120. doi:10.1007/s11336-008-9101-0.

Skinner, E. A. 1995. "Perceived Control." Motivation, \& Coping: Individual Differences and Development Series, Volume 8. Thousand Oaks, CA: SAGE Publications.

Skinner, E. A., and M. J. Belmont. 1993. "Motivation in the Classroom: Reciprocal Effects of Teacher Behavior and Student Engagement across the School Year." Journal of Educational Psychology 85 (4): 571-581. doi:10.1037/ 0022-0663.85.4.571.

Skinner, E. A., C. Furrer, G. Marchand, and T. Kindermann. 2008. "Engagement and Disaffection in the Classroom: Part of a Larger Motivational Dynamic." Journal of Educational Psychology 100 (4): 765-781. doi:10.1037/ a0012840.

Stroet, K., M. Opdenakker, and A. Minnaert. 2013. “Effects of Need Supportive Teaching on Early Adolescents' Motivation and Engagement: A Review of the Literature." Educational Research Review 9: 65-87. doi:10.1016/j. edurev.2012.11.003.

Taylor, G., T. Jungert, G. A. Mageau, K. Schattke, H. Dedic, S. Rosenfield, and R. Koestner. 2014. "A SelfDetermination Theory Approach to Predicting School Achievement over Time: The Unique Role of Intrinsic Motivation." Contemporary Educational Psychology 39 (4): 342-358. doi:10.1016/j.cedpsych.2014.08.002.

Tillema, H. H., M. J. M. Leenknecht, and M. S. R. Segers. 2011. "Assessing Assessment Quality: Criteria for Quality Assurance in Design of (Peer) Assessment for Learning-a Review of Research Studies." Studies in Educational Evaluation 37 (1): 25-34. doi:10.1016/j.stueduc.2011.03.004.

Vansteenkiste, M., W. Lens, and E. L. Deci. 2006. "Intrinsic versus Extrinsic Goal Contents in Self-Determination Theory: Another Look at the Quality of Academic Motivation." Educational Psychologist 41 (1): 19-31. doi:10. 1207/s15326985ep4101_4.

Vansteenkiste, M., and R. M. Ryan. 2013. "On Psychological Growth and Vulnerability: Basic Psychological Need Satisfaction and Need Frustration as a Unifying Principle." Journal of Psychotherapy Integration 23 (3): $263-280$. doi:10.1037/a0032359.

Vansteenkiste, M., E. Sierens, B. Soenens, K. Luyckx, and W. Lens. 2009. "Motivational Profiles from a SelfDetermination Perspective: The Quality of Motivation Matters." Journal of Educational Psychology 101 (3): 671-688. doi:10.1037/a0015083.

Vu, T. T., and G. Dall'Alba. 2007. "Students' Experience of Peer Assessment in a Professional Course." Assessment \& Evaluation in Higher Education 32 (5): 541-556. doi:10.1080/02602930601116896.

Wiliam, D. 2011. "What is Assessment for Learning?" Studies in Educational Evaluation 37 (1): 3-14. doi:10.1016/j. stueduc.2011.03.001.

Wollenschläger, M., J. Hattie, N. Machts, J. Möller, and U. Harms. 2016. "What Makes Rubrics Effective in TeacherFeedback? Transparency of Learning Goals is Not Enough." Contemporary Educational Psychology 44-45: 1-11. doi:10.1016/j.cedpsych.2015.11.003.

Wolterinck, C. H. D., S. Schildkamp, and A. J. Visscher. 2020. Formative assessment: influence of teacher competences and the role of students. Manuscript under review.

Wylie, E. C., and C. J. Lyon. 2015. "The Fidelity of Formative Assessment Implementation: Issues of Breadth and Quality." Assessment in Education: Principles, Policy \& Practice 22 (1): 140-160. doi:10.1080/0969594X.2014.990416. 